\title{
Simultaneous Detection of Protocatechuic Acid, Chlorogenic Acid and Caffeic Acid in Honey by HPLC with Ultraviolet and Electrochemical
}

\section{Detectors}

\author{
Zhongyin Zhang ${ }^{1}$, Wanqing Zhang ${ }^{1}$, Jianqiu Tu ${ }^{l}$, Yin Li ${ }^{1}$, Guangri X ${ }^{1}$, and Yuping Zhang ${ }^{1 *}$ \\ Henan Institute of Science and Technology, Xinxiang, 453003, China \\ *E-mail: zhangwqzzu@163.com, franklin525@126.com
}

doi: $10.20964 / 2018.07 .44$

Received: 13 January 2018 / Accepted: 1 May 2018 / Published: 5 June 2018

\begin{abstract}
A rapid and sensitive method for the detection of protocatechuic acid (PA), chlorogenic acid (CLA) and caffeic acid (CAA) has been developed by high-performance liquid chromatography (HPLC) with an ultraviolet detector (UV) and an electrochemical detector (ECD). HPLC with UV detection was performed on a $\mathrm{C}_{18}$ column $(250 \times 4.6 \mathrm{~mm}, 5 \mu \mathrm{m})$ with methanol $(\mathrm{pH} 4.0)$ - acetic acid $(\mathrm{v} / \mathrm{v}, 85 / 15)$ as the mobile phase at a flow rate of $1.0 \mathrm{~mL} / \mathrm{min}$. ECD detection was performed on a three-electrode system, with a glassy carbon electrode, a platinum foil and a saturated calomel electrode (SCE) as the working electrode, the auxiliary electrode and the reference electrode, respectively. Compared with individual HPLC-UV and ECD methods, the presented HPLC (UV-ECD) technique had the advantage of enhanced capture of electroactive PA, CLA and CAA and achieved obvious detection sensitivity. Under the optimized conditions, the linear concentration ranges were from 0.0005 to $6 \mathrm{mg} \mathrm{L}^{-1}$ for PA and CAA, and from 0.0015 to $18 \mathrm{mg} \mathrm{L}^{-1}$ for CLA, with limits of detection of $10 \mathrm{ng} \mathrm{L}^{-1}$ for PA, $30 \mathrm{ng}$ $\mathrm{L}^{-1}$ for CLA and $13 \mathrm{ng} \mathrm{L}^{-1}$ for CAA $(\mathrm{S} / \mathrm{N}=3)$, which were clearly lower than those obtained with the HPLC-UV method. The approach was also successfully applied to detection in honey samples with satisfactory recoveries.
\end{abstract}

Keywords: HPLC-UV method; HPLC-ECD method; HPLC (UV-ECD) technology; protocatechuic acid; chlorogenic acid; caffeic acid

\section{FULL TEXT}

(C) 2018 The Authors. Published by ESG (www.electrochemsci.org). This article is an open access article distributed under the terms and conditions of the Creative Commons Attribution license (http://creativecommons.org/licenses/by/4.0/). 